\title{
Aprendizagem Vicária de Treino de Toalete através de Filme de Animação: Estudo de Caso em Ludoterapia Comportamental
}

Vicarious learning in toilet training through an animated film: Case study of behavioral play therapy

Aprendizaje vicaria de entrenamiento de aseo a través de film de animación: Estudio de caso en ludoterapia de comportamiento
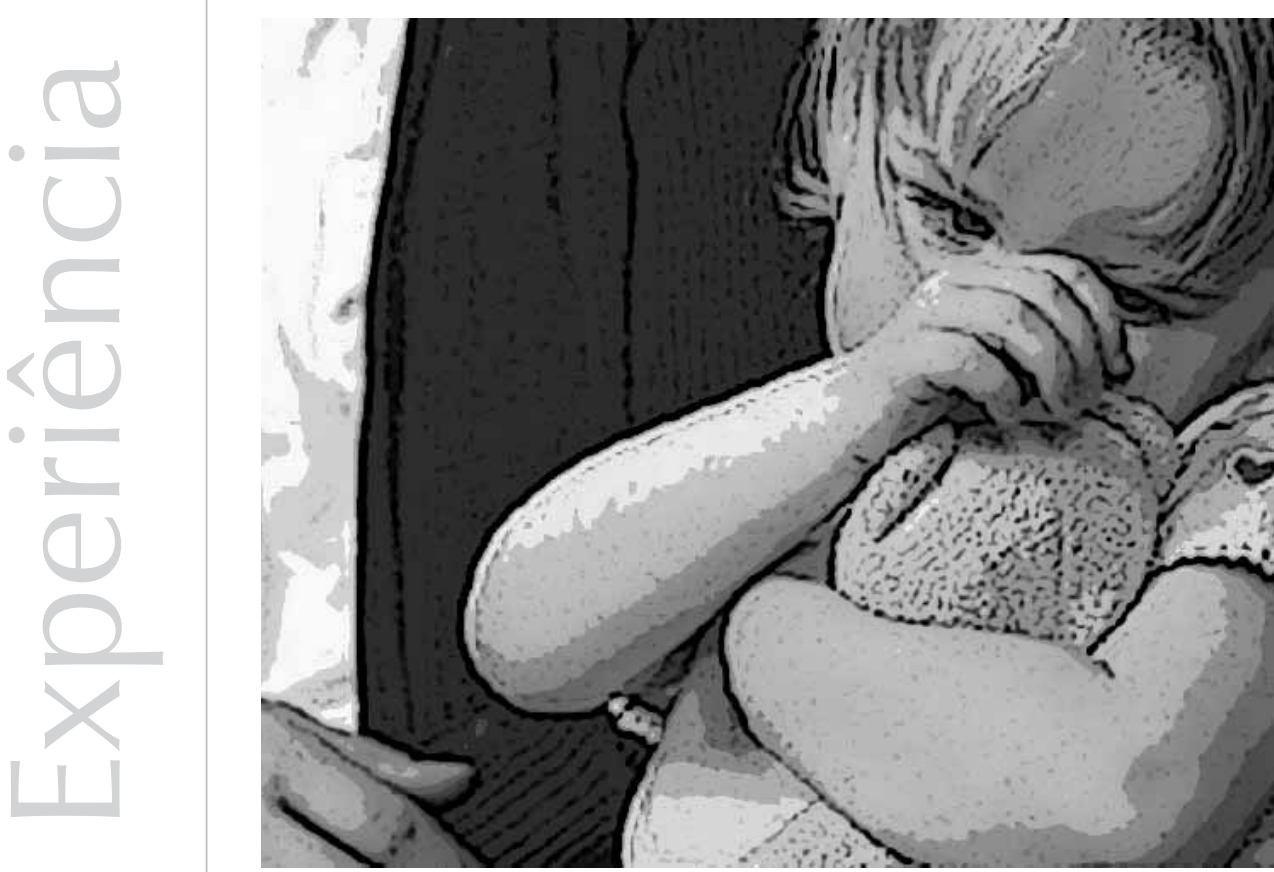
Resumo: Este trabalho consiste no relato do atendimento, em ludoterapia comportamental, de Lara (4 anos e 5 meses), que apresentava encoprese secundária retentiva, o que acarretava um intervalo entre as defecações superior a 72 horas. Método: a avaliação consistiu em entrevista com pais e babás, observação na escola, sessões lúdicas e sessões lúdicas familiares; as intervenções enfatizaram o uso de filme de animação, atividades lúdicas e brinquedos para obter a habituação comportamental e realizar o treino do toalete. Resultado: após a intervenção, utilizando filme de animação, Lara defecou no consultório, manteve o comportamento diário de defecação durante 18 meses de acompanhamento e apresentou três acidentes críticos nesse período. Discussão: o filme de animação é sugerido como a principal intervenção para a mudança de comportamento de Lara. Provavelmente, após observar os personagens do filme de animação realizando o treino de toalete e obterem adesivos, Lara foi reforçada vicariamente e aprendeu a relação entre o comportamento dos personagens (treino do toalete) e a conseqüência obtida por eles (adesivo). A brincadeira com as bonecas utilizadas no filme é concebida como um tipo de mediação lúdica.

Palavras-chave: Ludoterapia comportamental. Encoprese. Habituação. Aprendizagem vicária.

Abstract: This paper is a report of the treatment of Lara (4 years and 5 months old) who was experiencing secondary retentive encopresis, with an interval of over 72 hours between defecations. Methods: the evaluation was conducted through interviews with the parents and the nannies, observation at school, individual play sessions and family play sessions; the interventions focused on the use of animated films, play activities and toys to develop behavioral habits and toilet training. Results: after the intervention with the animated film, Lara defecated in the office and had daily defecations during the next 18 months of treatment; she had three serious accidents in this period. Discussion: most likely, after watching the characters' toilet training and the stickers they got in the animated film, Lara was vicariously reinforced and learned the relationship between the behavior of the characters (toilet training) and the consequent reward (sticker). The game with the dolls used in the film is considered a type of play mediation.

Keywords: Behavioral play therapy. Encopresis. Habituation. Vicarious learning.

Resumen: Este trabajo consiste en el relato del servicio, en ludoterapia de comportamiento, de Lara (4 años y 5 meses), que presentaba encoprese secundaria retentiva, que acarreaba un intervalo entre las defecaciones superior a 72 horas. Método: la evaluación consistió en entrevista con padres y niñeras, observación en la escuela, sesiones lúdicas y sesiones lúdicas familiares; las intervenciones enfatizaron el uso de film de animación, actividades lúdicas y juguetes para lograr la habituación de comportamiento y realizar el entrenamiento del aseo. Resultado: después de la intervención, utilizando film de animación, Lara defecó en el consultorio, mantuvo el comportamiento diario de defecación durante 18 meses de acompañamiento y presentó tres accidentes críticos en ese período. Discusión: el film de animación es sugerido como la principal intervención para el cambio de comportamiento de Lara. Probablemente, después de observar los personajes del film de animación realizando el entrenamiento de aseo y lograr adhesivos, Lara fue reforzada vicariamente y aprendió la relación entre el comportamiento de los personajes (entrenamiento del aseo) y la consecuencia lograda por ellos (adhesivo). La broma con las muñecas utilizadas en el film es concebida como un tipo de mediación lúdica.

Palabras-clave: Ludoterapia de comportamiento. Encoprese. Habituación. Aprendizaje vicario.

Apresentar autonomia nas atividades de vida diária na infância (vestir-se, banhar-se, escolha e preferência do vestuário, brinquedos, etc) significa realizar tarefas de graus variados de dificuldade em diversos contextos (escola, reunião social e familiar); realizar o treino de toalete corretamente (isto é, a execução de aproximadamente 17 etapas que tem início com a manifestação da vontade de ir ao vaso e termina com a limpeza das mãos) faz parte do desenvolvimento da autonomia do indivíduo (Windholz, 1988). A situação ideal, segundo Brazelton (1962), sugere que o treino de toalete ocorra aos 2 anos de idade, e deve ocorrer após observar-se plena prontidão para o treino, que ocorre, aproximadamente, aos 18 meses; sugere-se o critério de prontidão para o treino, em vez de práticas coercitivas; aos 24 meses, é iniciado o ensino passo-apasso do treino de toalete; aos 36 meses, através do reforçamento positivo (elogio pelo desempenho), do encorajamento (incentivo para a realização da tarefa) e da compreensão com a criança, é possível obter continência 
fecal; por fim, aos 48 meses, é completado o treino de toalete (Brazelton, 1962; Stadler, Gorski, \& Brazelton, 1999). No entanto, a "situação ideal" proposta por Brazelton (1962) não prevê o que fazer nos casos em que ocorre a recusa da criança em realizar o treino e "há falta de dados empíricos na literatura sobre esse fenômeno (a recusa em realizar o treino de toalete). Não há menção à recusa da criança de realizar o treino no estudo de Brazelton de 1962" (Taubman, 1997, p. 56).

Alguns estudos sugerem que a recusa da criança em realizar o treino está associada à experiência anterior de constipação, em que a criança apresenta dificuldade ou dor ao defecar (Blum, Taubman, \& Nemeth, 2004; Issenman, Filmer, \& Gorski; 1999). Segundo Fleisher (2004),

embora a constipação seja um elemento importante na patogênese da recusa em realizar o treino, nem toda criança que apresenta defecação dolorosa desenvolve aversão; por outro lado, nem toda criança que apresenta aversão ao toalete experienciou defecação dolorosa. Outros fatores, tais como a ansiedade, podem interferir na aprendizagem de toalete. (p. 1809)

A crítica de Fleisher (2004) à concepção de que a constipação é insuficiente para explicar o comportamento de recusa ao toalete implica modificações no ciclo de retenção proposto por Issenman, Filmer e Gorski (1999), em que a constipação produz, inicialmente, impactação fecal; a seguir, ocorre dor ao defecar, e, reiniciando o ciclo, a criança se recusa a usar o toalete. O ciclo de retenção proposto por Issenman, Filmer e Gorski (1999) desconsidera mudanças significativas na dinâmica familiar (separação dos pais, nascimento de irmão) e nas atividades de vida diária (retirada do leite materno e introdução de alimento novo, transição da fralda para o vaso no treino de toalete ou mudança de escola) que podem produzir aversão ao vaso. No treino de toalete, por exemplo, a tarefa dos pais é, através de instrução e exemplos, estabelecer gradualmente o uso do vaso em substituição ao hábito anterior de utilizar, de forma fácil e simples, a fralda para defecar ou urinar a qualquer momento. A ocorrência, durante esse período, de um evento aversivo (dor ao defecar ou medo de cair no vaso, por exemplo) ou novo (retirada súbita da fralda, nascimento de um irmão ou viagem), pode fazer com que a criança reaja intensamente, principalmente chorando e esquivando-se da tarefa de treino de toalete. À medida que os pais tentam estabelecer a transição da fralda para o vaso, a criança aumenta a intensidade da reação de recusa devido ao tipo de estratégia utilizada pelos pais (em geral, os pais estabelecem critério de defecação imediata no vaso e em grande quantidade, e apresentam dicas faciais de tensão quando não ocorre defecação). A recusa da criança em realizar o treino estabeleceu o quadro de aversão ao vaso.

Do ponto de vista psicológico, a reação de aumento na intensidade do choro e a recusa do uso do vaso é denominada sensibilização, definida como reação, de duração rápida ou longa, a mudanças bruscas no ambiente, cuja função é regular e organizar as inúmeras informações do ambiente distinguindo, por exemplo, entre estímulos nocivos e positivos (Domjan, 1996). O exemplo mais simples de sensibilização em bebês é a "resposta de orientação" do olhar ou o movimento da cabeça em direção a uma configuração de estímulos novos (brinquedos, pessoas, sons, etc). A característica principal da sensibilização é que ela não é específica a um determinado estímulo (Domjan, 1996); na primeira sessão de psicoterapia infantil, por exemplo, a criança inicialmente se recusa a explorar a sala, os brinquedos, e não interage com a terapeuta; nesse caso, a criança reage ao contexto lúdico de forma geral, em vez de reagir a um aspecto do contexto (à terapeuta ou a um brinquedo, por exemplo).

O ciclo de retenção fecal, descrito na Figura 1, baseia-se na proposta de Gomes (1998) e Coelho (2001) e inicia-se (ver Figura 1A) com a sensibilização, isto é, com a reação da criança a alguma mudança significativa no 
ambiente (por exemplo, reação de choro quando ocorre defecação com dor; resistência à nova babá; recusa da nova escola ou residência; irritação e birra diante da separação dos pais; choro e ansiedade no nascimento de irmão...). Nessa hipótese, a sensibilização gera, como subproduto, aversão e medo (cf. Kramprath \& Wotjak, 2004) de defecar no vaso; a aversão ao vaso faz com que a criança ignore as dicas fisiológicas e retenha as fezes; a retenção fecal por vários dias causa impactação fecal, dor, distensão abdominal e alterações comportamentais antecipatórias da dor (irritabilidade, recusa para realizar as refeições, aumento do número de brinquedos nas brincadeiras, diminuição da duração da atividade lúdica através do aumento da atividade de correr e apatia para brincar). Na última etapa do ciclo de retenção, após a administração de laxantes, medicações e dieta rica em fibras, a criança pode eliminar as fezes ressecadas devido ao padrão de retenção, ocorrendo o relato de dores e o reinício do ciclo de sensibilização de longa duração (Coelho, 2001).
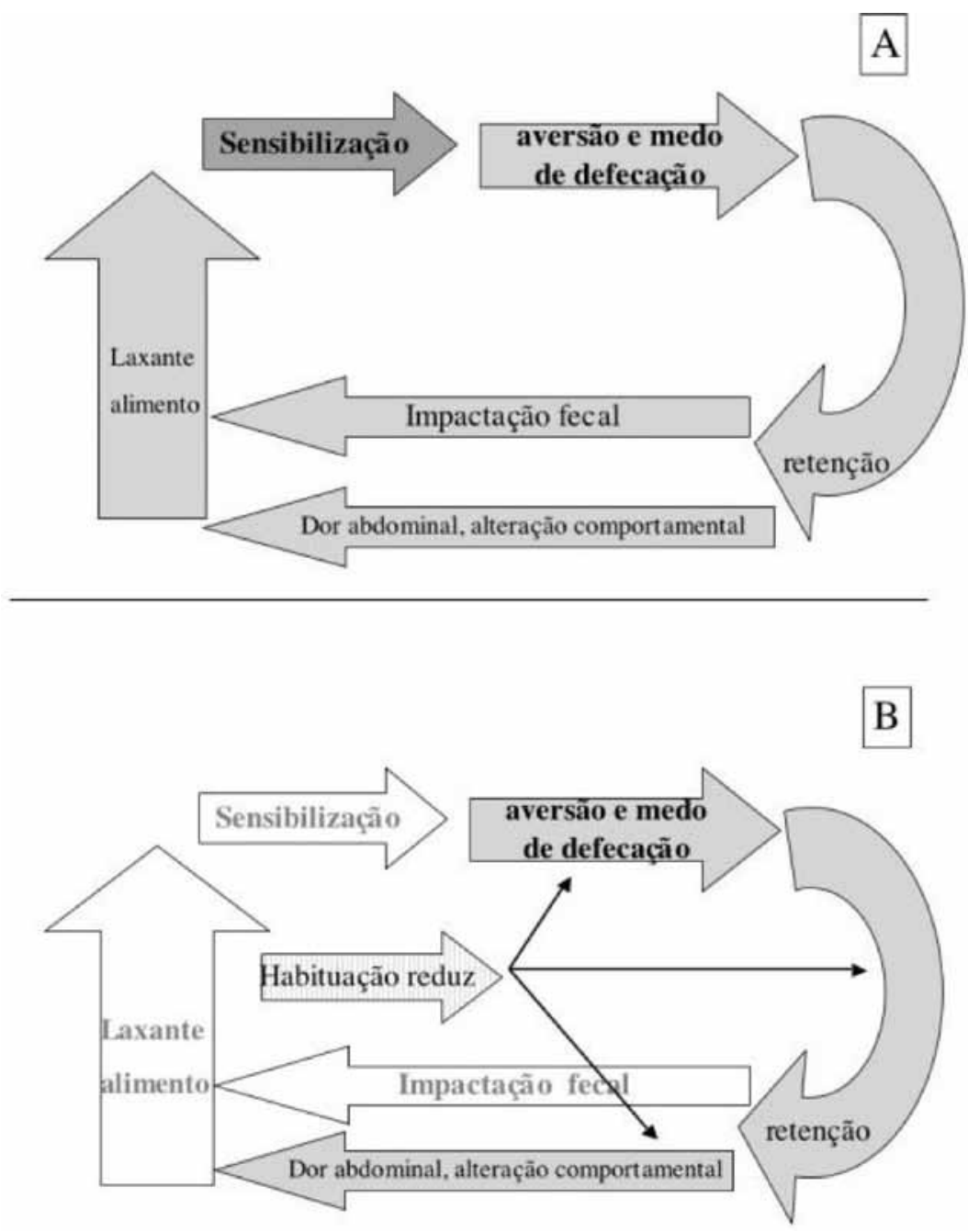

Figura 1. (A) O ciclo de retenção inicia-se com a sensibilização comportamental, que desencadeia aversão, medo e retenção fecal. A retenção acarreta dor, alteração comportamental e impactação. O uso de laxantes produz a defecação, a sensibilização e o início do ciclo. (B) A habituação comportamental ao toalete reduz o medo, o comportamento de retenção fecal e as dores abdominais e elimina o ciclo de retenção fecal. 
Segundo Taubman (1997), a recusa do uso do toalete pode gerar severa constipação, e, se não resolvida, gera encoprese primária.
Nessa perspectiva, o ciclo de retenção pode ser alterado através do processo de habituação (ver Figura 1B). Do ponto de vista psicológico, a habituação é definida como uma reação, de duração rápida ou longa, caracterizada pela diminuição progressiva na intensidade do comportamento (por exemplo, choro, retenção fecal e recusa do uso do vaso) à medida que o indivíduo é exposto ao estímulo desencadeador (por exemplo, o vaso ou o alimento que facilita a defecação). A habituação é o processo oposto à sensibilização, e caracteriza-se por ser uma reação a um estímulo específico, e, tal como a sensibilização, sua função é auto-reguladora e permite organizar as informações do ambiente (Domjan, 1996). No exemplo da resposta de orientação, a habituação ocorre à medida que a criança diminui, a cada repetição do evento, o movimento de cabeça em direção ao estímulo (som, cheiro, pessoa...); na primeira sessão lúdica, durante o atendimento clínico, observa-se habituação rápida quando a criança chega com a mãe ou o pai, observa o ambiente e imediatamente interage com a terapeuta, fazendo-lhe perguntas ou comentando sobre si ou sobre os brinquedos. Além de oponentes e autoreguladores, os processos de habituação e sensibilização são simultâneos.

Segundo Taubman (1997), a recusa do uso do toalete pode gerar severa constipação, e, se não resolvida, gera encoprese primária. A encoprese caracteriza-se pela: 1) ocorrência de evacuação repetida de fezes pela criança em locais inadequados de modo involuntário ou intencional, 2) idade superior a quatro anos ou nível de desenvolvimento equivalente, 3) freqüência no mínimo uma vez por mês durante três meses e 4) o comportamento não é decorrente de alteração fisiológica (Associação de Psiquiatria Americana, 2003). Descritivamente, a encoprese pode ser classificada como diurna ou noturna, primária (a criança que nunca conseguiu estabelecer controle esfincteriano) ou secundária (conseguiu estabelecer o controle por um tempo e perdeu-o sem conseguir retornar ao controle) e retentiva (a criança prende as fezes e permanece muitos dias sem defecar) ou não-retentiva, isto é, apresenta padrão diarréico.

As abordagens cognitiva e comportamental associadas à medicação são as mais indicadas para o tratamento da encoprese (Knell, 1995). Mais recentemente, a ludoterapia comportamental tem sido utilizada como uma forma alternativa de atendimento de crianças encopréticas, porque permite integrar estratégias comportamentais e/ou cognitivas nas atividades lúdicas com o objetivo de avaliar e intervir nas situações que causam sofrimento para as crianças e os pais (Gomes, 1998; Knell, 1995; Silvares, 2001). Uma importante estratégia de intervenção comportamental é o uso de filmes (Coelho, 2006; Thellen, Fry, Fehrenbach, \& Frautschi, 1979). Baseada no trabalho de Bandura sobre aprendizagem observacional ou vicária de modelos, a aprendizagem vicária através de filmes decorre de três processos: 1) a observação do modelo ao vivo ou em alguma mídia (filme, TV, revista em quadrinhos, recursos de hipermídia na internet...), 2) reforço ou punição vicária e 3) mediação (representação mental) cognitiva. Após a aprendizagem vicária, o aprendiz pode, imediatamente ou após longo intervalo de tempo, desempenhar a ação que observara. Segundo Bandura (1971), o observador pode ser reforçado ou punido durante a observação de um filme: se o comportamento do observador aumenta após observar o ator (ou modelo) ser reforçado por um comportamento similar, diz-se que houve reforço vicário; por outro lado, se o comportamento do observador diminui após observar o ator ser punido por um comportamento similar, diz-se que houve punição vicária. O observador forma uma representação cognitiva do comportamento do modelo e da conseqüência obtida; tal representação guiará o futuro comportamento 
do observador, que criará expectativas de obter conseqüências similares. Após a criança observar os personagens do filme de animação realizarem o treino de toalete e obterem adesivos, por exemplo, espera-se que ela seja reforçada vicariamente e estabeleça uma relação entre o comportamento dos personagens (treino do toalete) e o reforço obtido (adesivo).

O presente estudo de caso se refere ao atendimento de uma criança (denominada ficticiamente de Lara) com quadro de encoprese secundária retentiva; os objetivos foram: 1) investigar os fatores relacionados com o início e a manutenção do padrão de defecação, 2) analisar e explicitar o processo de habituação e sensibilização no contexto clínico, e 3) realizar a intervenção comportamental através de um filme de animação.

\section{A criança}

Lara, 4 anos e cinco meses, morava com os pais, o irmão e duas babás, e foi atendida no período de setembro a outubro de 2005; nesse período, Lara cursava a pré-escola em horário semi-integral e almoçava na escola. Lara foi caracterizada pelos pais como introvertida, tímida, ciumenta, carinhosa, e apresentava dificil adaptação a eventos novos. Gostava de assistir filmes infantis, brincar de bonecas e desenhar.

\section{Histórico da encoprese}

Segundo os pais, Lara apresentava padrão de defecação diário, geralmente pela manhã, e utilizava o vaso. A admissão na escola, a retirada da fralda e da mamadeira foram aceitas naturalmente quando Lara estava com 1 ano e oito meses. No segundo semestre de 2004, ela adaptou-se bem à nova escola e utilizava o vaso da escola. A mudança da babá ocorreu em fevereiro de 2005, período em que os pais viajavam freqüentemente a trabalho; Lara, nesse período, apresentou alteração comportamental (nervosismo, irritação e dificuldade em seguir regras e limites); em abril de 2005, os pais reduziram as viagens de trabalho e observaram melhora de comportamento da filha. Lara chorava, não queria ficar com a nova babá e sentia ciúmes do irmão de 2 anos e cinco meses. Em julho de 2005, os pais começaram a perceber ressecamento nas fezes, e a babá percebeu que Lara tinha medo de defecar. A mãe descartava a hipótese da alimentação, porque a filha tomava café e leite, almoçava na escola e não tivera problemas com a alimentação. No café da manhã, ela não recusava nenhum alimento; nas refeições, não ingeria frutas nem verduras. O pediatra receitou laxantes e supositórios, e Lara foi submetida a atendimento homeopático. Lara apresentou "intestino preso" em agosto de 2005 e, com dificuldade, eliminou fezes ressecadas com sangue, o que acarretou uma retenção de 4 a 6 dias. A mãe observou que Lara ficava no canto da sala escondida e irritada; numa visita à casa de amigos, ela defecou fezes ressecadas e de grosso calibre. A partir desse evento, Lara estabeleceu um padrão relativamente constante de 3 a 4 dias de retenção, com distensão abdominal. A conduta dos pais durante 15 dias, no período agosto-setembro, foi que a filha permanecesse por uma hora no vaso; Lara transpirava, chorava, verbalizava para a mãe que não queria ficar no banheiro e não gostava que a mãe a obrigasse a defecar; a mãe disponibilizava revistas, conversava, ministrava supositório e, após muita insistência para que Lara defecasse, ela defecava sob o efeito de alta dosagem de laxante. Nesse período, Lara defecou duas vezes no mesmo dia, na escola. A mãe observou que, durante a brincadeira, a filha estava retendo as fezes; explicou-lhe que não podia "segurar" as fezes e insistiu em que defecasse, mas Lara escondia-se atrás dos móveis e, após muito insistência, sentava no vaso e eliminava fezes ressecadas e com muita dor. Lara ficou contente por ter defecado, e 
ligou para a avó para contar que conseguiu ir ao banheiro. Contudo, voltou a "prender as fezes". Os pais informaram à psicóloga escolar sobre a dosagem de medicação, a possibilidade de Lara defecar na calcinha e solicitaram que a alimentação na escola (almoço e lanches) favorecesse a defecação. Os pais seguiram as orientações do pediatra em relação à medicação; estavam ansiosos e preocupados, porque era uma situação nova para eles, já que a filha não havia apresentado anteriormente dificuldades para defecar, e não sabiam qual atitude tomar em relação à retenção fecal: forçar Lara a sentar no vaso ou esperar que manifestasse a vontade? As medicações não estavam fazendo efeito, e o receio era que o intervalo entre as defecações fosse cada vez maior.

\section{Avaliação}

A avaliação foi concluída em 11 dias e consistiu nas seguintes etapas: entrevista com os pais (uma sessão), duas sessões lúdicas com Lara, duas sessões lúdicas familiares com a presença dos pais e do irmão, contato com as duas babás de Lara, uma visita à escola de Lara, uma sessão com os pais para entrega do laudo e uma sessão de intervenção com utilização de filme. Nas sessões lúdicas, observou-se e registrou-se o repertório da criança, tendo o registro incluído a duração na atividade lúdica, o tipo de brinquedo selecionado e a organização da brincadeira. As sessões foram filmadas e analisadas, a duração da habituação foi medida em minutos e os pais responderam a questionário de atividade de vida diária criado a partir da literatura em Psicologia (Windholz, 1988) e de entrevistas clínicas; um questionário específico sobre a encoprese foi criado a partir da literatura (DSM IV) e de entrevistas clínicas. Foi solicitado que os pais registrassem no calendário os dias das defecações, a consistência das fezes e a ocorrência de dores na tentativa de defecação.
A administração de laxante foi suspensa durante a avaliação, e o óleo mineral foi utilizado durante 10 dias. Diante da preocupação e solicitação dos pais sobre qual conduta deveriam seguir, foi orientado que não obrigassem Lara a ir ao vaso, e o tempo máximo que ela ficaria no vaso seria de 3 a 5 minutos.

\section{Sessões lúdicas de psicodiagnóstico}

\section{Primeira sessão lúdica}

Objetivos da sessão: estabelecer vínculo com Lara, observar o padrão de habituação e sensibilização ao ambiente, a escolha e a preferência de brinquedos, a interação com a terapeuta, a fim de se avaliar os prérequisitos necessários e motivadores para o uso de bonecas no treino do uso do vaso. Observou-se habituação longa de Lara à sessão a partir da sua reação ao ambiente lúdico (entrou na sala com o pai e, segurando um cão de pelúcia, verbalizou para o pai: "não tem nada aqui para brincar") e do início da interação verbal com a terapeuta (somente aos 10 minutos de sessão Lara respondeu a pergunta da terapeuta sobre o que gostava de brincar; aos 20 minutos de sessão, verbalizou espontaneamente, e somente aos 34 minutos de sessão explorou a sala, comentou e compartilhou as brincadeiras com a terapeuta). Lara aprendeu a utilizar a boneca do treino de toalete (colocar no vaso, apertar a mamadeira, fazê-la usar o vaso sanitário) o que indicava que ela tinha os pré-requisitos do treino de toalete. O vínculo de Lara com a terapeuta foi positivo; contou para a mãe que gostou e queria voltar, e quis continuar brincando mesmo após a sinalização do final da sessão. O padrão de brincadeira de Lara é característico do gênero feminino: casa de bonecas e atividades de vida diária, tais como trocar de roupas, horário das refeições e uso do vaso. Diante da habituação longa 
de Lara ao ambiente, decidiu-se que a melhor conduta seria que a próxima sessão fosse familiar, com duração de uma hora e meia, com os objetivos de: 1) favorecer a espontaneidade de Lara e 2) observar a dinâmica da interação familiar.

Segunda e terceira sessões lúdica-familiar

Objetivos: observar o padrão lúdico de Lara na interação familiar e a habituação. Esta última foi rápida; chegou sorridente com a família, entrou rapidamente na sala, explorou os brinquedos, sorriu durante a sessão e mostrou os brinquedos para a terapeuta. A interação familiar mostrou-se adequada, e Lara compartilhou com o irmão as brincadeiras de massa de modelar, pescaria e desenhos; brincou com a mãe de casa de bonecas e hospital, e o pai brincou de pescaria com os filhos. O irmão rapidamente habituou-se à sessão, acompanhou Lara nas atividades de exploração da sala e dos brinquedos, e houve brincadeira em duplas (Lara e o irmão, os pais com um dos filhos), trios (os irmãos com a mãe) e em conjunto. Os pais comentavam e elogiavam as brincadeiras dos filhos e aproximavam-se deles para compartilhar da atividade. Nas brincadeiras com todos os membros da família, os pais espontaneamente dividiram a atenção e estabeleceram limites adequados para os filhos. O objetivo dessa sessão foi alcançado, e Lara explorou os brinquedos espontaneamente; todos brincaram de forma harmônica e compartilharam as brincadeiras com a terapeuta.

\section{Quarta sessão lúdica}

Objetivos: favorecer a verbalização sobre os laxantes e as dores através da exposição a um brinquedo novo (kit médico), diversificar o padrão lúdico de Lara e iniciar o treino de toalete com bonecas utilizando as informações dos pais sobre o padrão de retenção e a recusa de Lara. A habituação de Lara foi rápida; chegou de bom humor e sorridente; conversou com a terapeuta 5 minutos depois de iniciada a sessão e, espontaneamente, após 10 minutos. Os objetivos de aumento da freqüência das verbalizações de Lara, a diversificação do padrão lúdico e o treino de toalete foram alcançados. Nas verbalizações de Lara, não foram contemplados as dores abdominais e os laxantes. Lara explorou o kit médico, sorriu durante a brincadeira compartilhada com a terapeuta e verbalizou sobre os instrumentos do kit médico. A intervenção do treino de toalete permitiu que Lara verbalizasse e participasse ativamente da atividade, conforme a seguinte passagem:

- (Terapeuta): "A Kelly fica prendendo xixi e cocô, e gostaria que você ajudasse a Kelly, ela diz que não consegue".

- (Lara): "O meu irmão prende xixi!"

- (Terapeuta): "É mesmo? Ele prende xixi?!"

- (Lara): "A minha boneca ajuda... ela é professora!"

- (Terapeuta): "A Kelly fala que não consegue!" _ (Lara): "A minha boneca é mais velha que a sua, ela é a professora. Deixe a Kelly vendo a gente desenhar e a outra boneca também".

\section{Observação na escola}

A visita à escola foi realizada no horário do recreio; Lara estava no banheiro com as colegas e uma delas estava defecando, e elas sorriam e conversavam. Lara e as amigas corriam pela escola e brincavam alegres e sorridentes. O contato com a psicóloga escolar mostrou que Lara apresentava boa adaptação à escola, era obediente; percebiam que o abdomem ficava ressaltado em alguns períodos e havia cuidado para que a alimentação favorecesse a defecação. Quando defecou na escola, Lara ficou bem, e a professora cuidou dela no banheiro. Lara gostava do ambiente escolar, e não havia indicativo de medo do vaso ou de alguma dificuldade com o seu uso na escola. 


\section{Entrevista com as babás}

A babá Naná (nome fictício) relatou que Lara tinha medo de fazer cocô, e sempre falava desse medo; Naná conversou com Lara e explicou que todas as pessoas vão ao banheiro. A alimentação dela era normal, não gostava de fruta, e era necessário brincar com Lara para que consumisse frutas. Há 45 dias, aproximadamente, observou que ela estava retendo as fezes; há dois meses não defecava todos os dias. Quando ficava sem defecar, alterava o comportamento, ficava nervosa e a barriga ficava "inchada"; quando ia ao banheiro, a barriga ficava menor e mostrava contente a barriga "murchinha". Quando defecava na calcinha, mostrava com vergonha a roupa suja. Lara aprendeu que alguns alimentos a ajudavam a ir ao banheiro, como, por exemplo, a laranja, mas não queria comer tais frutas. Em relação às brincadeiras, Naná relatou que Lara gostava de brincar sozinha no quarto com as bonecas. A informação sobre a brincadeira foi importante para planejar a sessão lúdica (evitar estereotipia no brincar) e avaliar os pré-requisitos para o uso de bonecos na intervenção no treino de toalete. A babá Dora (nome fictício) cuidava de Lara desde os 11 meses de idade, e relatou que Lara adorava comer caldo de feijão e arroz. Lara apresentava as fezes amolecidas diariamente, e, quando as fezes ficaram ressecadas e duras com maior freqüência, Lara perguntou se Dora sentia dor quando ia ao banheiro. Quando estava na fase de retenção, Lara ficava nervosa, não queria sentar no vaso e dizia que não tinha vontade de fazer cocô.

\section{Hipótese diagnóstica}

Baseado nos dados obtidos (sessões lúdicas, entrevista com os pais, entrevista com as babás, análise dos questionários de atividade de vida diária e encoprese, observação na escola e entrevista com a psicóloga escolar) foi elaborado e entregue aos pais o laudo (psicodiagnóstico) com a hipótese de que o início da recusa de defecação de Lara estava associado ao efeito de sensibilização, e a manutenção da recusa, ao ciclo de retenção. Lara provavelmente havia consumido alimento de difícil digestão, o que propiciou um intervalo maior que 24 horas, as fezes ficaram ressecadas e ela defecou com dor e sangue. Sucessivas ocorrências de defecação acompanhada de dor e dos demais efeitos de sensibilização (choro, irritação, recusa de ingestão de alimentação) gerariam o comportamento de esquiva do vaso. Nessa perspectiva, o padrão de esquiva era uma alternativa para fugir da dor; contudo, a retenção prolongada produzia o ressecamento das fezes, defecação mais dolorida do que a anterior, e obrigava-a a usar medicação (laxante e supositório).

\section{Intervenções - laudo}

Para alcançar o objetivo de favorecer a defecação e estabelecer o treino de toalete, os pais foram orientados a implementar o seguinte conjunto de medidas: 1) mudança do cardápio alimentar familiar (por exemplo, introdução de comida japonesa: shoyo, risoto japonês preparado com "gohan", saladas e azeite), e 2) observação das dicas comportamentais de funcionamento intestinal e registro dos horários das defecações. A estratégia para o treino de toalete foi: 1) os pais receberam kit de adesivos de personagens diversificados (Hello Kitty, Ariel, Bob Esponja, sapatilhas, coração e flores). Cada vez que Lara fosse ao vaso, ela ganharia um adesivo; a condição foi a de que, se ela tentasse defecar, então ganharia um adesivo pequeno, e, se ela conseguisse defecar, então ganharia o adesivo grande. O objetivo era que Lara ganhasse um adesivo com a simples tentativa. Na primeira semana, iniciariam o treino no vaso de 2 a 3 minutos e ensinariam a postura correta no vaso, 2) caso não conseguisse defecar no vaso, os familiares falariam que não tem problema, ela estava tentando e aprendendo a usar o 
vaso; 3) na segunda semana, colocariam Lara no vaso no horário mais favorável à defecação (de acordo com o registro dos pais), e 4) os pais deveriam manter o calendário para controle da defecação no vaso. Visto que, em termos de temperamento, Lara apresentava habituação longa a eventos novos e era resistente a mudanças bruscas no ambiente, o conjunto de medidas acima poderia ser de difícil aceitação por representar mudanças drásticas na rotina de Lara. Portanto, associado às orientações, foi proposto aos pais que, após cinco dias de implementação das estratégias do treino de toalete, fosse realizada uma sessão de intervenção lúdica, no consultório, utilizando filme de animação produzido especialmente para Lara, e cuja confecção e aplicação será descrita abaixo.

Foi levantada a hipótese de que, através de filmes de animação, poderia ser estabelecida: 1) a aprendizagem vicária das informações acerca do treino de toalete e a motivação para realizar o treino diariamente, e 2) a habituação comportamental ao treino diário, dado que o filme de animação fazia parte do hábito de Lara e, geralmente, não está associado a contextos de tensão emocional.

\section{Treino de toalete}

Os pais iniciaram o treino com a tentativa no toalete, com o uso de adesivos e com a mudança na alimentação (shoyo, azeite e ameixa e alimentação japonesa). Lara estava há seis dias sem defecar, e, no $1{ }^{\underline{a}}$ dia de treino de toalete, permaneceu quieta o dia todo; os pais sugeriram que ela brincasse na piscina, mas ela ficou pouco tempo na piscina e pediu para tentar fazer cocô, mas não conseguiu. Seguindo a orientação do pediatra, os pais administraram, inicialmente, alta dosagem de laxante, e, a seguir, óleo mineral; após essa intervenção, Lara defecou e chorou muito, provavelmente devido ao desconforto produzido pela alta dosagem de laxante administrado. No 2o dia de treino, realizou a tentativa relatando dor, e não defecou; no $3^{\text {o }}$ dia, sentiu dor, defecou e disse que não doeu; no 4 o e no $5^{\circ}$ dia, realizou o treino, relatou dor e não defecou.

\section{Sessão lúdica de intervenção filme de animação}

Após o quinto dia de treino de toalete de Lara, foi apresentado o filme de animação Um Dia de Boneca (http://br.youtube.com/ watch?v=ctvlvopOolU). Lara estava há 72 horas sem defecar. O objetivo do filme de animação foi apresentar, no contexto lúdico, tanto as atividades cotidianas do universo infantil (brincar de casinha, explorar as bonecas e as atividades de vida diária) quanto o treino de toalete que os pais tentaram implementar com Lara enfatizando a tentativa de defecar, o uso de adesivos e o cardápio sugerido para Lara (Coelho, 2006). Narrado ao vivo pela terapeuta, o filme apresentou a rotina de duas bonecas (Kelly e Amanda), que desempenhavam as seguintes atividades: o despertar da personagem que caminha em direção à cama de Amanda, despertando-a; a seguir, as duas tomam o café da manhã, há o uso do toalete, ocasião em que Kelly ensina a Amanda qual vaso usar e como marcar o adesivo no calendário; a seguir, as duas bonecas brincam de esconde-esconde e, por fim, assistem TV (Figura 2). A sessão lúdica de intervenção foi filmada com uma câmera Sony digital DCR TRV-140. Após explicar que seria apresentado um filme sobre bonecas que Lara conhecia, foi apresentado o filme com 4'02" minutos de duração, num notebook Apple com tela de 12 polegadas. O computador foi colocado numa mesa ajustada à altura de Lara, e, ao lado, foram dispostas as bonecas, as mobílias e o cenário utilizados no filme. A terapeuta realizou a seguinte narração ao vivo: 
_. (Kelly): Ah, eu tô acordando...o relógio...que preguiça...mas eu tenho que levantar, ah, quero ficar mais na cama, eu tenho que tomar café, tenho que fazer monte de coisa... eu acho que... eu acho que a Amanda está dormindo ainda, olha, ela está com os pés para cima, está muito escuro lá, não dá quase para ver. Ah, vou virar, ah, agora eu acordei! Vou ver a Amanda. AMANDA! AMANDA! ... Oi, eu vou te virar!, deixa eu ver aqui na minha janela ....Ah! você já levantou? Ah, vamos tomar café! Quer que eu te ajude?
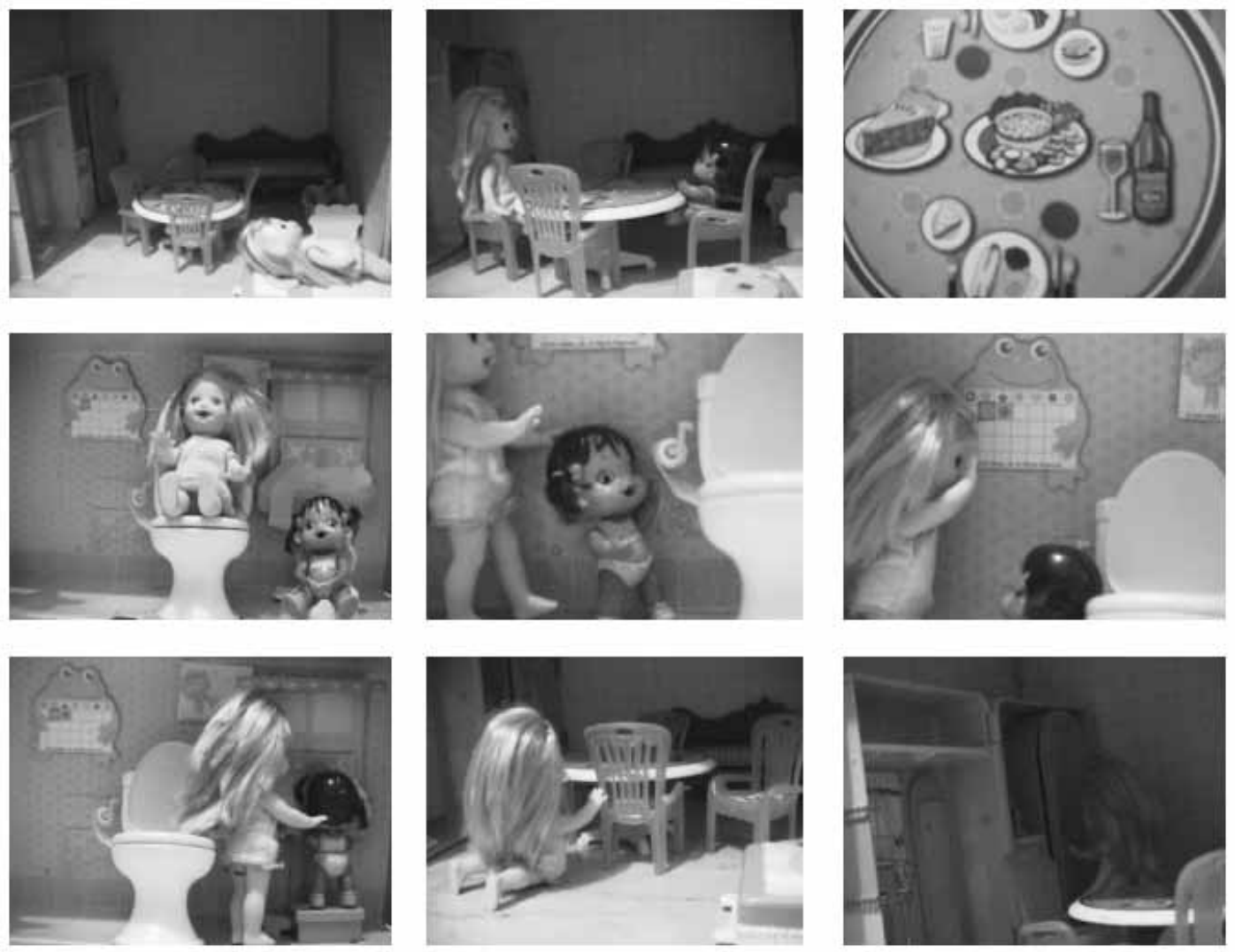

Figura 2. Sequências do filme de animação Um Dia de Boneca sobre o uso do toalete.

_ (Amanda): "Não precisa..."

_ (Kelly): "Olha nossa mesa, vamos tomar nosso café. Eu quero... tem bolo, torta, olha tem risoto (Lara olha o pincel e a folha e retorna o olhar para a tela; molha o pincel na tinta), - agora eu vou lá, eu vou lavar a mão, não, eu que vou para o banheiro agora, você não pode ir no grande, tem que ir no pequenininho aqui" (vaso grande e pequeno).

_. (Amanda): "Mas eu tô com vontade!"

_ (Kelly®): "Agora eu tô indo..."

_ (Amanda): "Eu também quero me limpar!"

_ (Kelly®): "Olha, eu vou colocar uma estrelinha, porque você tentou e eu também. Vamos lavar as mãos, você também; olha! jóia! E agora, o que a gente vai fazer?"

Lara interrompeu a narração do filme no momento em que as duas bonecas iniciaram a brincadeira de esconde-esconde; disse que utilizava calendário e que, quando fazia cocô, ganhava adesivos; a terapeuta investigou ("Você tem três adesivos?"), aproveitou a verbalização de Lara para instruir 
a boneca ("Boa idéia! Vou dar essa idéia para a Kelly também!") e tentou persuadi-la ("Então, quando você faz cocô, faz grande! Você vai ver que você vai fazer todo dia agora! Já tá fácil") conforme o seguinte trecho da conversação:

- (Lara): "Eu tenho (adesivos)... quando faço, eu tenho três adesivos".

_ (Terapeuta): "É mesmo?! Você tem três?!" _ (Lara): "Ahã!"

_ (Terapeuta): "Então você tá com um monte de adesivos também!"

_ (Lara): "Hã, hã, quando eu faço cocô, aí coloca grande."

_ (Terapeuta): "Olha que maravilha, Lara! Ela também! Boa idéia! Vou dar essa idéia para a Kelly também... então, quando você (Lara) faz cocô, faz grande. Você vai ver que você vai fazer todo dia, agora já tá fácil. Lara, você quer colocar voz na estorinha? (Lara balança a cabeça afirmativamente), então vou colocar a estória no início; aqui tem o microfone, quando quiser, pode começar!"

Lara solicitou que o filme fosse repetido duas vezes; o filme foi visto sem a narração, e Lara assistiu-o enquanto desenhava. Após assistir ao filme, Lara determinou, espontaneamente, que a próxima atividade seria brincar de treino de toalete com as bonecas e os cenários utilizados no filme. Foram realizadas três brincadeiras de treino de toalete, totalizando 13 minutos. A primeira brincadeira de treino de toalete durou 5 minutos. A brincadeira iniciou quando Lara disse que estava na hora de uma das bonecas fazer xixi ou cocô, e terminou quando a boneca usava o vaso e colava adesivo no calendário. Durante a brincadeira, Lara informou que possuía vários adesivos, e que a mãe colocava adesivo grande no calendário cada vez que ela usava o banheiro. Lara reconheceu que o calendário da boneca do filme com a figura de um sapo era igual ao dela. Terapeuta e Lara brincaram com as bonecas, oferecendo a mamadeira e colocando-as no vaso. A terapeuta incentivava a boneca ressaltando que ela deveria tentar; Lara incentivava a boneca a fazer força conforme o seguinte trecho da conversação:

_ (Lara): "Tá na hora da bonequinha fazer xixi". _ (Terapeuta): Tá na hora? Então posso pegála? Eu não estava lembrando que estava na hora. Vou pegar a mamadeira, eu acho que ela está mesmo com vontade!"

_ (Lara): "Por que?"

_ (Terapeuta): "Porque a calcinha dela já estava para baixo, ela já está tirando".

_ (Lara): "Eu não quero... se ela tentar não quer..."

_(Terapeuta): "Ela pode tentar, acho que quer, sim, é da turma do tentar".

_ (Lara): "Eu tenho um desse..."

_ (Terapeuta): "Tem um desse? Você quer dar a mamadeira ou eu dou? Você que sabe".

_ (Lara): "Você".

_ (Terapeuta): "Eu dou!? Então tá, nossa, Kelly! ....estou com sede". (Terapeuta prepara o vaso, a mamadeira e coloca a boneca no vaso) - "Está na hora de ir para o vaso".

-(Terapeuta imita voz de Kelly): - "Tá bom".

_ (Terapeuta): "Acho que está com muita vontade de fazer xixi".

_ (Terapeuta imita voz de Kelly)- "Eu tô..."

_ (Lara): "Cada dia ela tá segurando, cada dia ela..."

_ (Terapeuta)- "Cada dia ela tenta, não pode segurar, é para deixar o xixi sair e cocô também sair".

_(Terapeuta imita voz de Kelly):- "Tá bom, eu vou botar adesivo grandão no meu calendário".

(Terapeuta): "Isso, mesmo! Adesivo grandão. Ah, Kelly, então já sei! Vai ser do Bob Esponja". _ (Lara): "Não, na minha casa, minha mãe... no dia que que ela 'faze', é... minha mãe coloca para mim..." (sorri)

_ (Terapeuta coloca Kelly no vaso): "Ah! que bom!"

_ (Lara): - "Fazer força..."

_ (Terapeuta): - "Muito obrigada, Lara! Viu só, Kelly? Um pouquinho de força". 
A segunda brincadeira de treino de toalete durou 3 minutos. Terapeuta e Lara brincaram de escolher adesivos e colocaram uma das bonecas no vaso; Lara sorriu, incentivando a boneca a fazer força ("ela vai fazer cocô para eu colocar outro adesivo"), explorou o cenário da boneca, escreveu o nome das bonecas, disse que a boneca iria tentar novamente, e cantarolava. A brincadeira terminou quando a terapeuta disse que, se a boneca fosse tentar novamente, elas colocariam outros tipos de adesivos.

A terceira brincadeira de treino de toalete durou 5 minutos, e teve início com a verbalização:

_ (Lara): "Ela quer tentar!"

_ (Terapeuta): -"Ela quer tentar de novo!"

_ (Lara): "Eu acho que está na hora!"

_ (Terapeuta): "Tá na hora de tentar... então, vamos colocá-la de novo".

Lara sugeriu que as bonecas defecassem assistindo TV. Enquanto realizava a atividade de treino de toalete, Lara informava sobre as atividades na escola e desenhava. Lara descrevia com maior riqueza de detalhes as atividades, conforme o seguinte trecho da conversação:

_ (Lara):- "Abrir a perna" (abre as pernas da boneca no vaso).

- (Terapeuta):- "Abre a perninha...acho que deu para abrir, vou tirar a calcinha... ok" _ (Lara):-"Faz um cocô aí que eu vou fazer..." _ (Terapeuta cantarola): -"Vou fazer minha árvore...Kelly, tudo bem?"

_ (Terapeuta imitando Kelly):-“Tudo.."

_ (Terapeuta):- "Ótimo, muito bom..."

_( Lara):-“ Faz força, Kelly..."

_ (Terapeuta): - "Olha o que a Lara falou, ela está te ajudando, um pouquinho de força..." _ (Lara):-“Pouquinho..."

Após a terceira brincadeira de toalete, Lara decidiu brincar com a casa de bonecas; montou o cenário do toalete e compartilhou a brincadeira com a terapeuta. Três minutos após iniciar a brincadeira com a boneca, Lara foi ao toalete fazer xixi e defecou sem o auxílio da terapeuta; a pedido de Lara, a mãe entrou na sala e elogiou o desempenho da filha. A mãe foi convidada a permanecer na sala e assistir ao filme. Lara cantou e colocou a boneca para defecar diante da TV.

\section{Resultados}

Após defecar durante a sessão lúdica de exibição do filme, Lara defecou diariamente, sem apresentar recusa para usar o vaso, utilizando o toalete da escola e consumindo alimentos variados conforme sugerido na avaliação, além de ameixas à noite e pela manhã; o óleo mineral foi retirado no dia seguinte após a exibição do filme. Lara apresentou três acidentes críticos com padrão diarréico (defecou na calcinha duas vezes, na escola, e em casa, 8 e 11 dias após a sessão lúdica de intervenção, respectivamente). Os acidentes críticos deixaram de ocorrer após a redução do consumo de ameixas.

\section{Acompanhamento}

O acompanhamento foi realizado via e-mail e telefone, com a mãe, no período de novembro/2005 a abril/2007. Segundo a mãe, o calendário contribuiu para o controle da rotina de uso de toalete, reduzindo a ansiedade diante do quadro de encoprese da filha e permitindo-os ajudá-la sem cobranças; Lara espontaneamente se dispunha a realizar o treino várias vezes seguidas e gostava de colocar o adesivo no calendário. Quando era sugerido ir ao toalete, Lara dizia que iria tentar; freqüentemente folheava revistas enquanto permanecia no vaso e, por fim, conseguia defecar. Os pais avaliaram que Lara estava mais tranqüila, carinhosa e receptiva. 
O uso do calendário e dos adesivos foi retirado em dezembro de 2005. O contato com a psicóloga da escola, em abril de 2006, mostrou que Lara estava bem, não apresentava alteração comportamental nem distensão abdominal e utilizava o toalete da escola. Em abril de 2007, a mãe relatou que Lara apresentava bom funcionamento intestinal e recebia incentivo dos pais para ir ao toalete.

\section{Discussão}

O padrão de retenção fecal de Lara pode ser descrito pelo ciclo de retenção do seguinte modo: inicia-se com a sensibilização, isto é, defecação dolorida nos meses de junho e julho de 2005, o que gera aversão e medo de defecar no vaso (Lara verbalizava que sentia dor ao defecar; a aversão ao vaso fez com que ela ignorasse as dicas fisiológicas e retivesse as fezes); a retenção fecal por vários dias causou impactação fecal, dor, distensão abdominal e alterações comportamentais antecipatórias da dor (irritabilidade, recusa para realizar as refeições e apatia para brincar). Na última etapa do ciclo de retenção, sem dieta rica em fibras, mas com a administração de laxantes, Lara eliminou fezes ressecadas e relatou dores.

Lara já havia adquirido o treino de toalete, mas conhecia somente a situação de defecação sem dor, estava iniciando uma nova aprendizagem: a defecação pode estar associada, algumas vezes, à dor e ao desconforto. A entrevista com a babá mostrou que, para Lara, a defecação estava associada à dor, e ela buscava informações para formar um julgamento (por exemplo, a crença de que ela não era capaz e/ou que, no seu caso particular, defecar era difícil e causava dor). A crença ou o julgamento de auto-eficácia seria um subproduto ou conseqüência de quatro fontes de informações: modelos significativos para Lara (babá, colegas da escola), estados emocionais e somáticos (por exemplo, dor e desconforto), sucesso ou insucesso na realização da tarefa de treino de toalete e das tentativas de persuasão verbal dos pais e familiares (Bandura, 1994). A intervenção, que utilizou filmes de animação e brincadeiras ao vivo com as bonecas do filme, pode ter criado um contexto em que as quatro fontes de informações estavam presentes: modelo (bonecas preferidas por Lara), dicas sobre estados somáticos do modelo (boneca defeca sem dor), persuasão verbal na interação entre as bonecas e sucesso do modelo ao realizar o treino.

A hipótese explicativa para a mudança observada no padrão de defecação de Lara é que o filme de animação produziu efeitos de habituação, isto é, diminuição progressiva na intensidade do comportamento de recusa de Lara em realizar a tentativa de defecação no vaso à medida que era exposta, a cada repetição do filme, ao contexto específico de uso do vaso. Dado que a habituação é o processo oposto à sensibilização, o filme pode ter possibilitado a exposição ao contexto de uso do vaso sem que os efeitos de sensibilização ocorressem em graus elevados de intensidade. Os efeitos de habituação do filme de animação provêm do uso de música, do movimento das bonecas, da narrativa e das bonecas, mobílias e atividades apresentadas no filme (brincadeira de esconde-esconde, uso de adesivos e calendários), que eram familiares a Lara; tais componentes do filme são incompatíveis com a ativação emocional de ansiedade e apreensão no treino de toalete ao vivo, em que o indivíduo pode sentir dor ou falhar na tentativa de defecar. A habituação produzida pelo filme reduziria os comportamentos de recusa do vaso, retenção fecal e reações comportamentais decorrentes da retenção (irritabilidade, apatia e recusa em consumir alimentos) que compõem o ciclo de retenção.

Além de produzir efeitos de habituação, observar o filme parece ter resultado na aprendizagem de determinadas relações. Por exemplo, a relação entre o uso do toalete / preenchimento do calendário com adesivos, uso do toalete / brincadeira de escondeesconde pode ter sido aprendida através 
da observação vicariante dos modelos. Pode-se inferir tal aprendizagem pelas três brincadeiras realizadas por Lara, logo a seguir, com as bonecas, em que ela simula a situação de uso do toalete seguida pela marcação do calendário com adesivos ou por uma atividade de lazer (por exemplo, ver TV tal qual apresentada no filme). Embora os pais de Lara tenham dado adesivos grandes e pequenos após a tentativa de defecar, o filme apresenta duas personagens que obtêm êxito na tarefa e recebem adesivos pelo desempenho correto. A aprendizagem vicária da relação uso do toalete/prenchimento do calendário e uso do toalete/brincar de esconde-esconde parece ter ocorrido na primeira apresentação do filme, porque, nas duas repetições subseqüentes, Lara observava cenas que tinham pouca relação com a tarefa de uso do toalete (por exemplo, Lara olhou para a tela principalmente quando a cena apresentava fundo musical). A aprendizagem vicária foi possível porque: 1) as bonecas do filme funcionaram como modelos para Lara (as bonecas utilizadas no filme foram escolhidas como modelos a partir da observação da atividade lúdica de Lara e da entrevista com a babá), 2) Lara assistiu o modelo recebendo adesivos após defecar, e 3) as três atividades lúdicas realizadas após o filme funcionaram como mediadores para a defecação no toalete do consultório (mediação lúdica), permitindo a prática manifesta de seqüências do treino de toalete.

A mediação lúdica, imediatamente após o filme, através das bonecas, mobílias e cenários, pode ter feito com que Lara ensaiasse aspectos do treino de toalete (dificuldades que ocorrem no treino, preenchimento de calendário com adesivos e verbalizações de incentivo para prosseguir na tarefa). A mediação lúdica ou ensaio com brinquedos é equivalente ao que Bandura chama de "operações de ensaio manifesto", e difere do "ensaio encoberto", no qual a pessoa observa e aprende com o modelo, mas não desempenha nenhuma resposta manifesta. Segundo Bandura (1969), o nível de aprendizagem observacional "pode ser consideravelmente desenvolvido através da prática ou do ensaio manifesto de seqüências de respostas modeladas, especialmente se o ensaio for encaixado após segmentos naturais de um padrão modelado mais amplo" (p. 81). O ensaio com brinquedos talvez seja o modo mais eficaz para uma criança de 4 anos resolver determinados problemas, porque, no desenvolvimento das habilidades lingüísticas e cognitivas que facilitam o brincar de faz-de-conta, a criança pré-escolar comumente utiliza objetos que podem assumir as funções de seres vivos ou de outros objetos (um pedaço de pau pode representar um cavalo, por exemplo).

O presente estudo de caso clínico em consultório privado objetivou contribuir para a prática profissional da psicoterapia infantil 1) relatando de modo detalhado um estudo de caso no qual foram aplicados conceitos de aprendizagem observacional, 2) detalhando o processo de tomada de decisão em um ambiente dinâmico, que aponta o julgamento que o clínico precisa fazer de acordo com as informações que os pais, os técnicos da escola e os dados de observação fornecem. Procurou-se ressaltar que o ambiente clínico é dinâmico, no sentido de que muitos eventos ocorrem simultânea e paralelamente, e podem estar correlacionados ou independentes, e 3) onde se tentou reduzir as ameaças à validade interna utilizando dados objetivos, avaliação contínua e efeitos imediatos e acentuados das intervenções (Del Prette, Silvares, \& Meyer, 2005). Estudos clínicos posteriores devem utilizar delineamentos que permitam aumentar a validade interna do procedimento de filme de animação (por exemplo, delineamento de linha de base ou linha de base múltipla). 


\section{Laura dos Santos Gomes Coelho}

Especialista em psicometria, especialista em psicologia clínica pelo Conselho Federal de Psicologia

Endereço para envio de correspondência:

SCN Q.2 Bloco D Torre B, sala 322 - Centro Empresarial Liberty Mall - Brasília- DF - Brasil CEP 70712-903

E-mail: lauragcoelho@mac.com

Associação de Psiquiatria Americana. (2003). DSM-IV-TR-Manual diagnóstico e estatístico de transtornos mentais. Porto Alegre: Artes Médicas.

Bandura, A. (1969). Modificação do comportamento. Rio de Janeiro: Interamericana.

Bandura, A. (1971). Psychological modeling: Conflicting theories. Chicago: Aldine-Atherton.

Bandura, A. (1994). Self-efficacy. In V. S. Ramachaudran (Ed.), Encyclopedia of human behavior (Vol. 4, pp. 71-81). New York: Academic Press

Blum, N. J., Taubman B., \& Nemeth, N. (2004). During toilet training, constipation occurs before stool toileting refusal. Pediatrics, 113, 1809-1810.

Brazelton, T. B. (1962). A child-oriented approach to toilet training. Pediatrics, 29, 121-128.

Coelho, L. S. G. (2001). Encoprese e constipação em gêmeos: um estudo de caso em ludoterapia comportamental. Psicologia: Ciência e Profissão, 21, 1-13.

Coelho, L. S. G. (2006). Efeitos de filme de animação em encoprese retentiva: um estudo de caso em ludoterapia comportamental. In XV Encontro da Associação Brasileira de Psicoterapia e Medicina Comportamental (p. 30).

Del Prette, G., Silvares, E. F. M., \& Meyer, S. B. (2005). Validade interna em vinte estudos de caso comportamentais brasileiros sobre terapia infantil. Revista Brasileira de Terapia Comportamental e Cognitiva, 8, 93-106.

Domjam, M. (1996). The essentials of conditioning and learning. Pacific-Grove, CA: Brooks/Cole.

Fleisher, D. R. (2004). Understanding toilet training difficulties. Pediatrics, 113, 1809-10.
Gomes, L. S. (1998). Um estudo de caso de encoprese em ludoterapia comportamental. Psicologia: Ciência e Profissão, 3, 54-61.

Issenman R. M., Filmer, R. B., \& Gorski, P. A. (1999). A review of bowel and bladder control development in children: How gastrointestinal and urologic conditions relate to problems in toilet training. Pediatrics, 103, 1346-1352.

Kamprath, K., \& Wotjak, C. T. (2004). Nonassociative learning process determine expression and extinction of conditioned fear in mice. Learning and Memory, 11, 770-786.

Knell, S. M. (1995). Cognitive behavioral play therapy. New Jersey: Aronson.

Stadler, A. C., Gorski P. A., \& Brazelton, T. B. (1999). Toilet training. Methods, clinical interventions, and recommendations. Pediatrics, 103, 1359-1361.

Silvares, E. F. M. (2001). Ludoterapia cognitivo-comportamental com crianças agressivas. In H. J. Guilhardi, M. B. B. P., Madi, P. P. Queiroz, \& M. C. Scoz (Eds.), Sobre comportamento e cognição. Expondo a variabilidade (pp. 189-198). Santo André, SP: ESETec.

Taubman, B. (1997). Toilet training and toileting refusal for stool only: A prospective study. Pediatrics, 99, 54-58.

Thellen, M. H., Fry, R. A., Fehrenbach, P. A., \& Frautschi, N. M. (1979). Therapeutic videotape and film modeling: A review. Psychological Bulletin, 86, 701-20.

Windholz, M. H. (1988). Passo a passo, seu caminho. São Paulo: Edicon. 